\title{
ACQUISITION IN A LARGE IT ORGANIZATION
}

\author{
Agata SZYDELKO
}

\begin{abstract}
This article explores the background, challenges and paradoxes of the NATO IT acquisitions, highlights the drivers of change in NATO procurement processes and procedures, and explains the underlying evolutionary nature of this change. It provides comparative analysis of acquisition models used by NATO and its agencies, emphasising the importance of agility and adaptiveness to changing circumstances.
\end{abstract}

Keywords: acquisition, IT, organization, agile, change, evolution.

\section{Introduction}

The IT acquisitions performed on behalf of the 29 NATO nations are key elements of NATO's defence and deterrence posture. Transparent and unbiased procurements, underpinning delivery of NATO capabilities and services, require a set of proper frameworks, policies, procedures, processes and people to turn the requirements into deliverables. The world is evolving - and so should NATO IT acquisitions; but do they really evolve in an adequate manner? This article provides an overview of past and current challenges and solutions and outlines expected developments in NATO acquisition of IT technologies and systems.

\section{Evolution of NATO IT acquisition}

In 1996, NATO revised its procedures for acquisition of commonly funded infrastructure under the NATO Security Investment Programme (NSIP). The procedures promoted full and open competition - International Competitive Bidding (ICB) - as the default procurement method, with the lowest compliant bid as the evaluation methodology, and were geared primarily to the acquisition of static IT infrastructure.

Not surprisingly, this construct did not survive contact with real-time NATO operations triggered by the crisis in the Balkans in the late 1990's. To improve NATO's ability to better respond to crisis situations, in 2002 the NATO nations approved a set of procedures aimed to significantly shorten procurement timelines and, at the same time, promote the broader participation of the small and medium enterprises in 
NATO procurements through the so called Basic Ordering Agreement (BOA) Programme. ${ }^{1}$

The unfolding NATO operations in Afghanistan led to a further consolidation of the regulations for the NATO Security Investment Programme (NSIP) ${ }^{2}$ in 2011, providing a set of procedures covering non-article 5 NATO-led operations, i.e. the Alliance Operations and Missions (AOM) NSIP Procurement Regulations.

In parallel, in 2009 the NATO nations also approved a policy for conducting international competitive bidding using a Best Value evaluation methodology.

So it looks like all regulations and other prerequisites are available - small and big scale procurements, lowest compliant and best value evaluation, peacetime and operations-geared procedures. Is there anything that we are missing? In fact, one can argue that there are remaining challenges, as well as opportunities to improve NATO's acquisition of IT systems. ${ }^{3}$

\section{Paradoxes of NATO IT procurement regulations}

There are a couple of paradoxes that mark the landscape of the NATO IT acquisitions when it comes to the NATO procurement regulations.

The most fascinating paradox, which is so much embedded within the NATO system that is hardly regarded as being anything out of ordinary, is that the fundamental criteria determining the applicable procurement procedures is ... the source of funding. At the very top of all of the NATO procurement regulations are the NATO Financial Regulations - the NFRs, but right below there are three separate sets of procurement procedures - one for the NSIP, one for the Military Budget (MB), and one for the Civil Budget (CB). As the NSIP funds NATO investment in new infrastructures and systems, the MB pays for their follow-on operations and maintenance, and CB covers operation and maintenance of the NATO Headquarters. This ultimately implies that different sets of procedures apply to the different stages of a system's lifecycle.

Another interesting aspect is that all NSIP contracts are, by rule, Firm Fixed Price (FFP) contracts. More flexible and innovative approaches to contract pricing, widely known and used in national systems, like incentive or performance based contracts do not exist in the NSIP regulations. Therefore, the only way to try to get NATO a better deal than a lowest compliant FFP contract is to opt for a best value FFP. But here comes another paradox - in the best value competitions the default weighting between the top level criteria, price and technology, is ... 50-50. Changing the weighting to account for greater share of the technology aspect must be properly justified and agreed by the Investment Committee (IC). Ultimately, due to the default 50-50 rule, even in the best value competition it is still the lowest priced bid that stands the greatest chance of winning. 
It can be expected that, over the coming years, there will be efforts aimed at closing the gaps created by these paradoxes - continuation of bottom-up enhancements, leading at some point to an adjustment of the overarching policies and procedures.

\section{Changing Dimensions of NATO IT Acquisition - Agile}

Over the past years, the use of NSIP regulations to develop state of the art software has proven to be very challenging, with all the weaknesses of using the traditional waterfall approach. Extensive consultations have been conducted since 2015 amongst NATO stakeholders on how to reshape the NATO approach to software intensive projects.

Very recently, in mid-2017, the Investment Committee agreed on the use of an agile approach for the procurement of technology intensive projects and authorized the first software procurement that will emphasize certain Agile aspects. In this initial Agile approach, the procurement mechanisms will be kept within the boundaries of existing rules and regulations, with a FFP contract that prioritizes time at completion rather than the delivery of every element of the defined scope. Control of contractor performance, while enhanced by the use of some Agile techniques-like the use of iterative development, incremental time-boxed deliveries, the use of burn-down charts and regular user feedback at the end of each time-box-will also rely on the established mechanisms of a FFP contract. A key enabler will be the greater involvement of the end-user community in the lifecycle of the project, helping to clarify and prioritize requirements and validate deliveries.

Clearly, the adoption of Agile in NATO would be phased progressively, and only once it demonstrates the initial benefits, the case for more fundamental changes in the NATO regulations can be made.

This may sound very conservative and cautious, but is indeed a real breakthrough and an important milestone in the evolution of the NATO procurement. It also proves that finding solutions to most difficult problems in NATO acquisitions does not necessarily require immediate and revolutionary changes to procurement procedures, but rather the exploration of innovative ways of applying them.

\section{Consolidation - Key Drive of Optimization}

The NATO Agencies Reform was a major undertaking, instigated on the request of the NATO nations and aimed at optimization and savings through consolidation of the NATO Agencies. The establishment of the NCI Agency in 2012 was one of the key outcomes of this reform, which for the first time in NATO history consolidated within a single NATO body all the organizational elements involved in the development, delivery and support of NATO C4ISR capabilities - a true lifecycle approach. 
This allowed not only for the consolidation of the procurement regulations at the NCI Agency level, but also for the instigation of consolidated planning of NATO C4ISR procurements across the NATO budgets, thus promoting competition and driving down the cost through economies of scale.

Interestingly, the advantages of consolidation are visible also in case of procuring consultancy manpower. Establishment of a support services contract, covering all the short- to mid-term consultancy services required across the Agency, was a game changer at the time of the first consolidated solicitation back in 2009, and was followed by the second contract edition in 2015. International Competitive Bidding for the third edition of the support services contract will lead to multiple contract awards in generic and specialist support areas over 2018.

Consolidation of the procurement actions also allows for having a greater menu of choices with respect to the model employed for provision of the IT services, in particular in the areas of NATO missions and operations, like the Balkans or Afghanistan, where reliance on the fully outsourced - Contractor Owned and Contractor Operated IT-might be considered as the most beneficial for the Alliance.

\section{Driving Change in NATO Acquisitions}

In this spirit of continued evolution, NCI Agency is preparing a review of the BOA Programme in order to implement lessons learned throughout the fifteen years of its operation - making the programme leaner and more comprehensive at the same time. The review will include an update of the BOA categories and procedures as well as revision of the BOA terms and conditions to encompass aspects specific to software, service and consultancy contracts. In addition, the BOA application package will be reduced and simplified to make the Programme more accessible to all C4ISR Industries.

At the same time, the NCI Agency is contributing to the efforts aiming at acceleration of the acquisitions related to the cyber domain. Last but not least, the Agency is working towards expanding cooperation with national Not-For-Profit organizations across the NATO nations in the area of science, research and development, thus complementing the well-established and explored collaboration with national Industries.

\section{Conclusion}

Continued evolution of NATO procurement frameworks, processes, policies and procedures is the key in ensuring properly measured acquisitions and enabling Alliance readiness and responsiveness, while at the same time maximizing competition through unbiased and transparent solicitations.

Twenty years back, the NSIP procurement regulations at their heart were meant to get NATO solid hardware IT infrastructures. Today, we outsource IT for NATO mis- 
sions, provide network operations and maintenance through service level agreements, develop state of the art C4ISR software or acquire specialist consultancy services. There is a broader set of tools-BOA Programme, Best Value, Agile-while all they are rooted in the same core procurement regulations. The introduction of all the novelties was indeed evolutionary - through pilots, trial periods, revisions and careful assessments. None required a revolution, but all are based on consensus of all the members of the Alliance working together towards the same goal of peace and security.

The world is evolving, and so is NATO IT acquisition.

\section{Acknowledgement}

I dedicate this paper to all my colleagues from the NCI Agency Acquisition Directorate, who, through their daily commitment and hard work bring the continued improvement and embrace the change in the NATO IT acquisitions.

\section{Disclaimer}

Any opinions expressed herein do not necessarily reflect the views of the NCI Agency, NATO and the NATO nations but remain solely those of the author.

\section{Notes}

1 "Basic Ordering Agreement Orders (BOA)," NATO Communications and Information Agency, accessed October 10, 2017, https://www.ncia.nato.int/Industry/Pages/BasicOrdering-Agreements-BOA.aspx.

"NATO Security Investments Programme," Allied Command Transformation, accessed October 10, 2017, http://www.act.nato.int/nsip.

3 This article presents the practitioner's point of view. For theoretical approaches the readers may refer to, for example, National Research Council, Achieving Effective Acquisition of Information Technology in the Department of Defense (Washington, D.C.: National Academies Press, 2010); Kenneth Nidiffer, Suzanne Miller, and David J. Carney, Potential Use of Agile Methods in Selected DoD Acquisitions: Requirements Development and Management, CMU/SEI Report no. CMU/SEI-2013-TN-006 (Pittsburgh, PA: Software Engineering Institute, Carnegie Mellon University, 2014), http://resources.sei.cmu.edu/library/asset-view.cfm?AssetID=89158; Aleksandar Dimov, Gueorgui Stankov, and Todor Tagarev, "Using Architectural Models to Identify Opportunities for Improvement of Acquisition Management," Information \& Security: An International Journal 23, no. 2 (2009): 188-203. 


\section{About the author}

AGATA SZYDELKO received a Master's degree in Management and Marketing at Wroclaw University of Economic. In 2012 she graduated from NATO Executive Development Programme. Since 2016 she is Deputy Director of Acquisition in NATO Communications and Information (NCI) Agency.

Previously, in her role of NCI Agency Principal Account Manager, Agata led the establishment of five multinational projects and Communications and Information Partnerships with several NATO and Partner nations, and established the first online NCI Agency Customer Services Catalogue. Before that, as NCI Agency Senior Contracting Officer in charge of C4ISR acquisitions in support of ISAF and KFOR, and software enterprise agreements, she coordinated the Basic Ordering Agreements Programme. She has held posts of International Business Director and Sales and Marketing Director in national IT industry.

In recognition of her work at NATO, in 2015 Mrs Szydelko was presented with a Medal of Merit for National Defence by the Polish Minister of National Defence. 